\title{
Results from 28 years of newborn screening for congenital adrenal hyperplasia in Sapporo City
}

\author{
Katsura Ishizu*, Akie Nakamura', Kaori Fujikura², Masaru Fukushi ${ }^{3}$ Tomoyuki Hotsubo ${ }^{4}$, Taiko Sasaki², \\ Toshihiro Tajima ${ }^{1}$ \\ From 7th APPES Biennial Scientific Meeting \\ Nusa Dua, Bali. 14-17 November 2012
}

Newborn mass screening (MS) for congenital adrenal hyperplasia $(\mathrm{CAH})$ was started in 1989 at nationwide of Japan. To date, the goals for prevention of life-threatening salt-wasting crises and prevention of incorrect sex assignment in virilized females are almost achieved. However in Sapporo city, which is located in the northern part of Japan, a pilot study was started in 1982 after the assessment of its feasibility and efficiency.

Here we report the results of MS from 1982 to 2010 in Sapporo city.

In 28 years, 17-hydroxyprogesterone (17-OHP) was determined in MS samples in 498,147 newborns and a total of 2,466 screened newborns had abnormal 17OHP. Among them, 26 patients were diagnosed with 21-hydroxylase deficiency (21-OHD), which corresponds to a prevalence of $1: 19,160$ live birth in Sapporo city. It is almost identical to the worldwide incidence of $\mathrm{CAH}$.

Among 26 patients, 20 patients were classified into saltwasting forms, 5 patients were classified into simple virilizing forms and one was classified into nonclassic forms. 19 patients were female and 7 patients were male. Two familial cases were detected. The mean examination day of 25 patients (data of one patient was not available) was 6.4 days after birth (from 0 to 18 days). Among 18 female patients, 11 patients were clinically suspected because of virilization prior to MS result becoming available and were referred to neonatal center. 4 female patients were referred after MS screening. One female patient was assigned to male after birth; however the patient was diagnosed as having 21-OHD by MS and the sex was changed after the diagnosis. One female patient was a familial case and during pregnancy prenatal treatment was done and her genitalia was normal female. Another one patient having

'Department of Pediatrics, Hokkaido University School of Medicine, Sapporo, Japan

Full list of author information is available at the end of the article normal female genitalia and no symptom, was diagnosed as nonclassic forms by MS. By contrast to female patients, all 7 male patients were detected by MS.

Another type of CAH was not detected in our study.

In conclusion, MS for CAH in Sapporo city can be considered reliable.

\section{Authors' details}

'Department of Pediatrics, Hokkaido University School of Medicine, Sapporo, Japan. ${ }^{2}$ Sapporo City Institute of Public Health, Sapporo, Japan. ${ }^{3}$ Sapporo Immunodiagnostic Laboratory, Sapporo, Japan. ${ }^{4}$ Department of Pediatrics, NTT East Japan Sapporo Hospital, Sapporo, Japan.

Published: 3 October 2013

doi:10.1186/1687-9856-2013-S1-P115

Cite this article as: Ishizu et al:: Results from 28 years of newborn screening for congenital adrenal hyperplasia in Sapporo City. International Journal of Pediatric Endocrinology 2013 2013(Suppl 1):P115.

Submit your next manuscript to BioMed Central and take full advantage of:

- Convenient online submission

- Thorough peer review

- No space constraints or color figure charges

- Immediate publication on acceptance

- Inclusion in PubMed, CAS, Scopus and Google Scholar

- Research which is freely available for redistribution
C Biomed Central

ㄷ 2013 Ishizu et al; licensee BioMed Central Ltd. This is an Open Access article distributed under the terms of the Creative Commons Attribution License (http://creativecommons.org/licenses/by/2.0), which permits unrestricted use, distribution, and reproduction in any medium, provided the original work is properly cited. 